\title{
Soil crack morphology analysis using image processing techniques
}

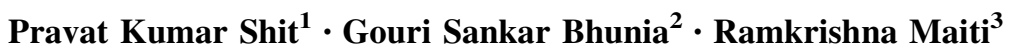

Received: 24 September 2015/ Accepted: 30 September 2015/Published online: 3 November 2015

(C) Springer International Publishing Switzerland 2015

\begin{abstract}
The present paper demonstrated an image processing technique of surface soil crack analysis. The geometric features of cracks, such as width, length, and surface area are estimated. These parameters are important, because they influence both the soil hydraulics and mechanics. The crack intensity factor was introduced as a descriptor of the extent of surficial cracking. The correlation analysis indicates that area-weighted mean ratio of soil-crack area to perimeter and index $r$ has a much closed positive relationship with cracks intensity and the area weighted mean of crack fractal dimension declines continuously as the degree of development of soil cracks increases, indicating that the degree of complexity of the soil cracks also gradually decreases. However, traditional visual assessment, which is the primary method in use, is slow and expensive. The present works involve image processing technique for the automatic detection and analysis of cracks in the digital image of a concrete surface.
\end{abstract}

Ramkrishna Maiti

ramkrishnamaiti@yahoo.co.in

Pravat Kumar Shit

pravatgeo2007@gmail.com

Gouri Sankar Bhunia

rsgis_gouri@rediff.com

1 Department of Geography, Raja N.L.Khan Women's College, Gope Palace, Medinipur 721102, West Bengal, India

2 Bihar Remote Sensing Application Centre, IGSC Planetarium, Bailey Road, Patna 800001, India

3 Department of Geography and Environment Management, Vidyasagar University, Medinipur 721102, West Bengal, India
Keywords Soil cracks - Fractal geometry - Photography techniques · GIS techniques

\section{Introduction}

Cracks on upper surface of soil can appreciably influence the soil performance in a variety of agricultural, geotechnical and environmental sectors. Though wetting and drying cycle because of seasonal changes of weather can be a dynamic force for dehydration cracking, climate change could potentially exacerbate the harmful effects (Gore 2006; Tang et al. 2010). Soil cracking is a multifaceted process that persuades soil properties, plant growth, and the movement of water and solutes in soil (Bandyopadhyay et al. 2003; Xiong et al. 2009). Earlier studies suggested that soil cracks are directly connected to changes in soil structure (Velde et al. 1999; Bruand et al. 2001), infiltration capacity (Chenwuing et al. 2003), evaporative loss of soil water, volume shrinkage (Tang et al. 2011) and the special movement of soil solutes (Roberto 2002). Adrian et al. (2000) stated that soil cracks cause worsening in soil water quality and persuade several significant physical, chemical, and biochemical processes in the soil (Yoshida et al. 2004). Studying soil cracks has significant importance in understanding the soil degradation processes and subversive pollution of water and the expansion of re-vegetation practices (Xiong et al. 2008). Chertkov (2000) affirmed that crack networks in the soil directly depend upon the hydraulic properties of soil. Desiccation cracks are also observed on the surface of natural clayey soil slopes. These cracks expose the interior of soil slopes to climatic changes, thereby allowing further cracking to occur. Many researches indicated that soil-crack morphology qualitative descriptions, through complex network structure of soil 
cracks (Novak 1999; Vogel et al. 2005; Uday and Singh 2013) and it significantly influences the hydraulic properties of the soil.

Several quantitative measurements have been done to identify soil cracking process. However, crack area density and length density determines the connectivity of crack's network (Vogel et al. 2005). Xiong et al. (2008, 2009) studied crack length, width and other morphological characteristics to understand the connectivity and complexity of the soil cracks. Tang et al. (2010) established that desiccation cracking patterns crack development through moisture content, stiffness and tensile strength of soil, and base adhesion. Dasog and Shashidhara (1993) used lengths of string to measure crack length within one square meter. The original crack pattern is often disturbed by human activities and equipments, which usually results in large measurement errors. The advancement in the computer software capabilities has made image analysis a new and efficient tool that can be applied to process crack images (Lakshmikantha et al. 2009; Liu et al. 2011). Tang et al. (2008) investigated the influence of several factors on the geometrical structure of desiccation crack patterns based on image processing. Therefore, the present paper, quantify the surface crack fractal geometry extracted by image processing techniques.

\section{Materials and methods}

\section{Study area}

The present study carried out on lateritic gully basin landscapes, located in Rangamati badland of Paschim Medinipur district, West Bengal, India (Fig. 1). The Rangamati badlands, cut in upper lateritic and mudstone, occur on steep slopes developed between Quaternary pediments and have a restricted vertical extension with a maximum local relief of up to $50 \mathrm{~m}$. They are relatively young and have only development since the dissection of one of the younger surfaces of the Rangamati badland (Shit et al. 2014, 2015). On these slopes there is a full range of erosional forms from discontinuous gullies to deep linear gullies. The study area experiences tropical monsoon climate having a prolonged dry period. Annual rainfall of the region is about $1850 \mathrm{~mm}$, and almost $70 \%$ of total rainfall concentrates in the monsoon period. Temperature of the catchment area varies from 48 (May-June) to $10{ }^{\circ} \mathrm{C}$ (December-January).

\section{Field investigation and sampling}

Field survey was conducted near the Cossi River at Medinipur town, from August, 2014 to May, 2015 respectively.
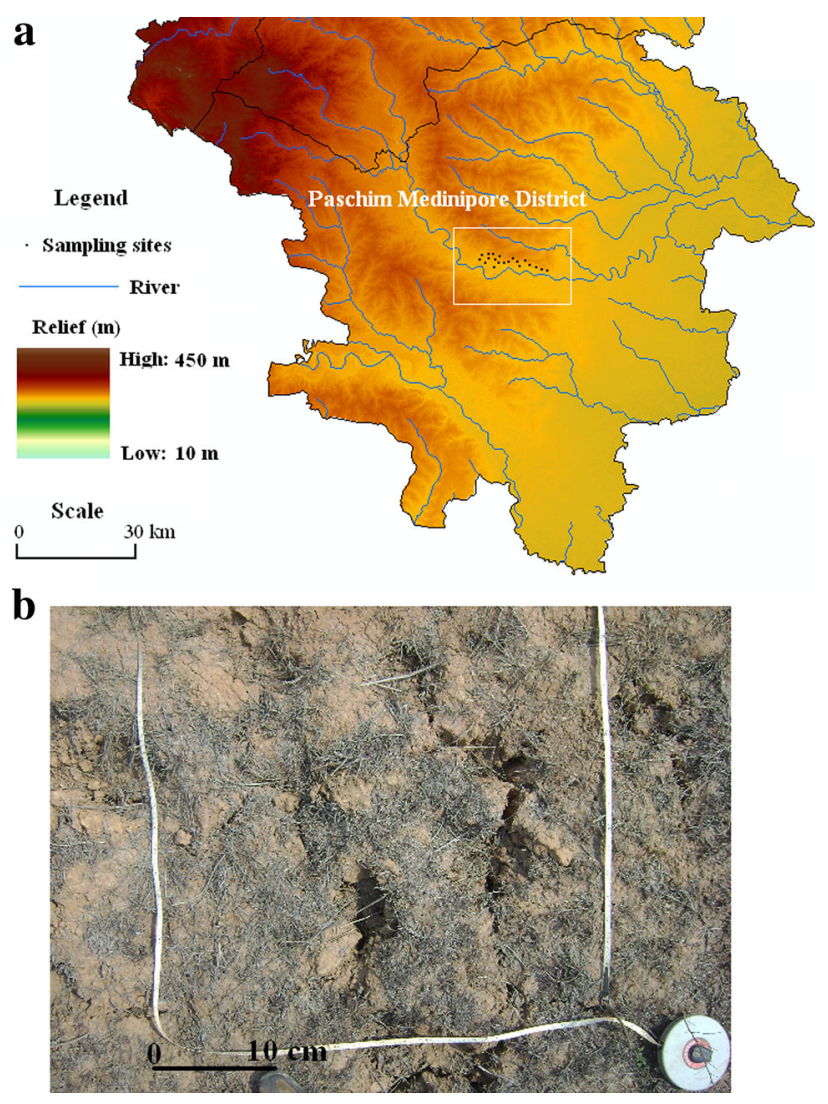

Fig. 1 Location of the study area: a sampling sites; b field photograph

The physical properties of the study area are presented in Table 1. Soil cracking in the study area was divided into five grades, namely feeble development, slight development, medium development, intensive development and extremely intensive development, and quadrats investigations were carried out for each grade. A total 20 crack quads (Size $400 \mathrm{~mm} \times 400 \mathrm{~mm}$ ) were selected which represent the different degrees of development of soil cracks. The photos of the field were collected using normal

Table 1 General characteristic of the soil properties

\begin{tabular}{lc}
\hline Soil properties & Value \\
\hline Grain size analysis & \\
Sand (\%) & 45 \\
Silt (\%) & 35 \\
Clay (\%) & 20 \\
Organic matter (\%) & 4.3 \\
Base saturation (\%) & 79.86 \\
pH & 5.6 \\
Specific gravity & 2.87 \\
Liquid limit (\%) & 73 \\
Plastic limit (\%) & 38 \\
Plasticity index & 37 \\
\hline
\end{tabular}


digital camera (7.2 mega pixel) after clearing up all the weeds and the images were processed indoors.

Image acquisition, processing and analysis

A total 20 samples were taken between August, 2014 and May, 2015 to obtain bare soil images for estimation of cracks morphology. Images were taken from approximately $1 \mathrm{~m}$ height horizontally to the ground. The area for each image was about $0.1225 \mathrm{~m}^{2}(0.35 \mathrm{~m} \times 0.35 \mathrm{~m})$ and a reference scale was used to obtain similar soil surface areas for the difference soil cracks. All images were taken with identical camera setting having best shoot function using flash light, with out any zoom and having constant focus area (Bauer and Strass 2014). The images were further processed in laboratory (Fig. 3). The co-ordinate of the sample locations were collected through global positioning system (GPS). The images were analyzed through ERDAS v.8.software. Images were registered in ERDAS Imagine v8.5 using the GPS co-ordinate point based on 2nd order polynomial transformation and nearest neighbour resampling method. After coordinate correction, digital image processing and topological transformation, the geometric characteristics of crack patterns such as length, perimeter and area of each soil crack were extracted from the processed images (Liu et al. 2013; Lee et al. 2013; Jianhua et al. 2015). Figure 2 represents the flowchart of proposed methodology.

\section{Estimation of intensity of soil cracks}

Intensity of soil cracks $\left(D_{c}\right)$ is one of the main dominating factors of soil-crack morphology and degree of development of soil cracks processes. The morphological intensity of soil cracks was calculated by the linear or planar elements of surface cracks' morphology (Novak 1999) using following formula.

$D_{c}=\sum_{i=1}^{n} a_{c} / A \times 100 \%$

where, $D_{c}$ Soil-crack area density; $a_{c}$ the sum of all soilcrack areas in the typical cracked soil (in $\mathrm{mm}^{2}$ ), and A the total surface area of the typical cracked soil (in $\mathrm{mm}^{2}$ ).

\section{Soil cracks' morphological complexity}

In the present study, the concepts of fractal geometry and network analysis are applied to measure cracks' morphological complexity. The ratio of soil-crack area to perimeter is defined as the ratio of the area of a soil crack to its perimeter. Crack fractal dimension is an effective tool to measure an object's complexity, whose value

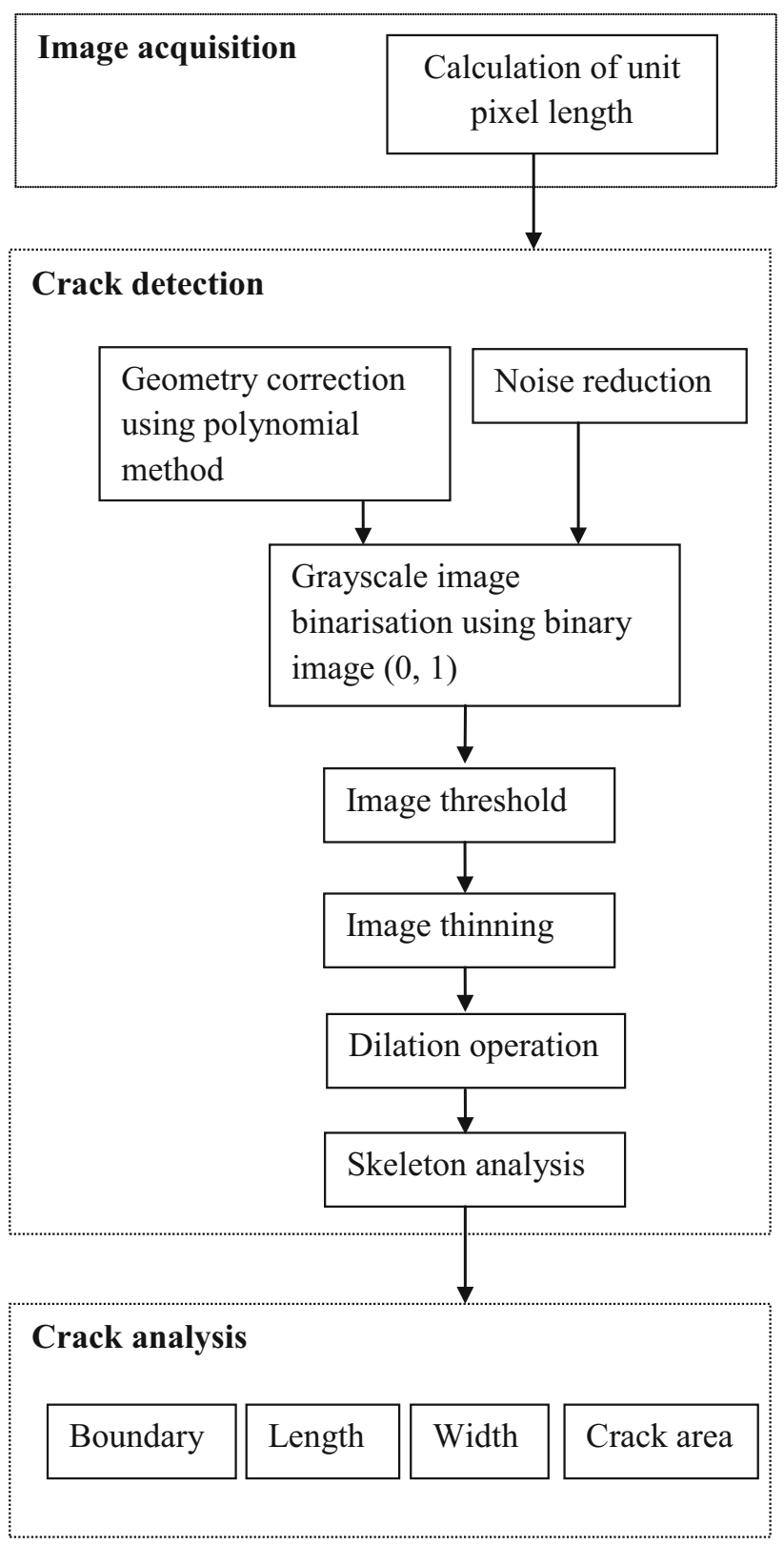

Fig. 2 Flowchart of the methodology (after modified Lee et al. 2013)

ranges between 1 and 2 . The more complicated an object represents the greater value of fractal dimension (Chen and Ling 1998). Therefore, area-weighted mean ratio of soil-crack area to perimeter (AWMARP) and the area weighted mean of crack fractal dimension (AWMFRAC) are both applied to express the crack's complexity. The fractal dimension was calculated by the following equations:

$A W M A P R=\sum_{i=1}^{m} j=\sum_{j=1}^{n}\left[\left(\frac{a_{c i j}}{P_{c i j}}\right)\left(\frac{a_{c i j}}{A_{c}}\right)\right]$ 
$\mathbf{a}$
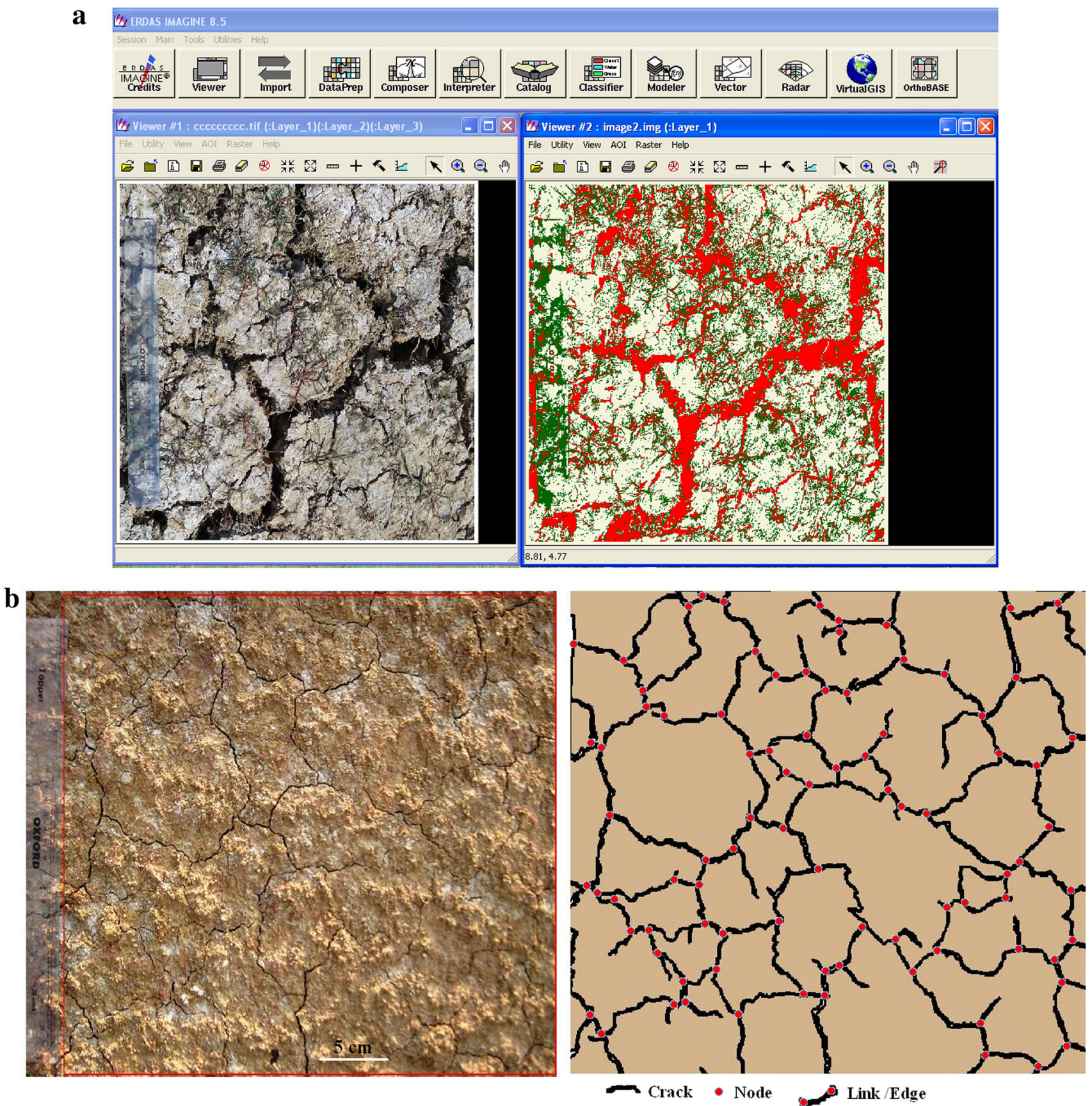

Fig. 3 a Original crack image (left) and image classification (right), b soil-crack quad photo before (left) and after image processing (right)

where cij $a$ is the surface area of a soil crack (in $\mathrm{mm}^{2}$ ), cij $P$ is the perimeter of a soil crack (in $\mathrm{mm}$ ), and $A_{\mathrm{c}}$ is the total area of all soil cracks (in $\mathrm{mm}^{2}$ ).

AWMFRAC $=\sum_{i=1}^{m} \sum_{j=1}^{n}\left[\frac{2 \ln \left(0.25 P_{c i j}\right)}{\ln \left(a_{c i j}\right)}\left(\frac{a_{c i j}}{A}\right)\right] / N$

where, $\mathrm{c}_{i j} P(\mathrm{~mm})$ is the crack's perimeter, $\mathrm{c}_{i j} a\left(\mathrm{~mm}^{2}\right)$ is the crack's area; A is the total surface area of the typical cracked soil (in $\mathrm{mm}^{2}$ ); $\mathrm{N}$ is number of observation.

\section{Soil cracks' morphological connectivity}

Spatial variation of soil cracks' morphological properties is analysed through connectivity. Connectivity is connection of soil cracks topology. Index $r$ is the ratio of connected crack number and the maximum possible number of connected crack. Equation 4 was applied for calculated the connectivity index.

$r=\frac{L}{L_{\max }}=\frac{L}{3(V-2)}$ 
where, $\mathrm{L}$ is the number of connected cracks; $\mathrm{V}$ is the number of the crack nodes. $L_{\max }$ is the number of maximum possible connected cracks. Index $\mathrm{r}$ ranges between 0 and 1 . The greater its value is, the higher the crack's connectivity.

\section{Results and discussion}

Table 1 shows the geometrical characteristic of soil cracks. The average length was $127.0 \mathrm{~mm}$ with SD of $62.16 \mathrm{~mm}$. In Fig. 4a correlation analysis indicates that AWMARP has a very close positive relationship with $D_{c}\left(R^{2}=0.727\right)$. This result shows the significant growth in the average width of soil cracks, especially in the stages of intensive development of soil cracks (Xiong et al. 2009).

Figure $4 \mathrm{~b}$ presents the index $\mathrm{r}$ value against density of cracks, $D_{c}$. Generally, as $D_{c}$ values increase, the index $r$ also increases logarithmically, indicating that soil-crack connectivity grows continuously with increasing degree of development of soil cracks (Table 2). This reflects the fact that soil cracks do not develop in isolation but are interconnected. The number of interconnected soil cracks rises during the process of soil-crack development, resulting in enhanced connectivity. Soil-crack connectivity refers to the degree of connection between or spatial continuity of soil cracks. This is an important property related to the migration efficiency of water and solutes in soil. The index $r$ is an indicator often used to measure the connectivity of a network (Xu 2002). Larger values of this index indicate greater connectivity of soil cracks. A correlation analysis indicates that index $r$ has a significant relationship with $D_{c}$ (correlation coefficient $=0.801$ )

Area-weighted mean ratio of soil-crack area to perimeter (AWMARP) is one of the crack fractal dimensions of soil. The ratio of soil-crack area to perimeter is defined as the ratio of the area of a soil crack to its perimeter. The mean value of AWMARP is $3.4 \pm 1.95$ (Table 3). Figure $4 \mathrm{~b}$ indicated close positive relationship between AWMARP and $D_{c}\left(\mathrm{R}^{2}=0.727\right)$. This result shows the significant growth in the average area of soil cracks, especially in the stages of intensive development of soil cracks. Our results also corroborated with the previous findings (Xiong et al. 2009).

Area weighted mean of crack fractal dimension (AWMFRAC) is one indicator of the soil crack's complexity and it's calculated the crack fractal dimensions. The average and SD value of AWMFRAC are 1.436 and 0.243 respectively (Table 3 ). Figure $4 \mathrm{c}$ showed that there is a negative exponential correlation between soil fractal dimension and density of soil cracks. The result shows that AWMFRAC declines continuously as the degree of development of soil cracks increases, indicating that the
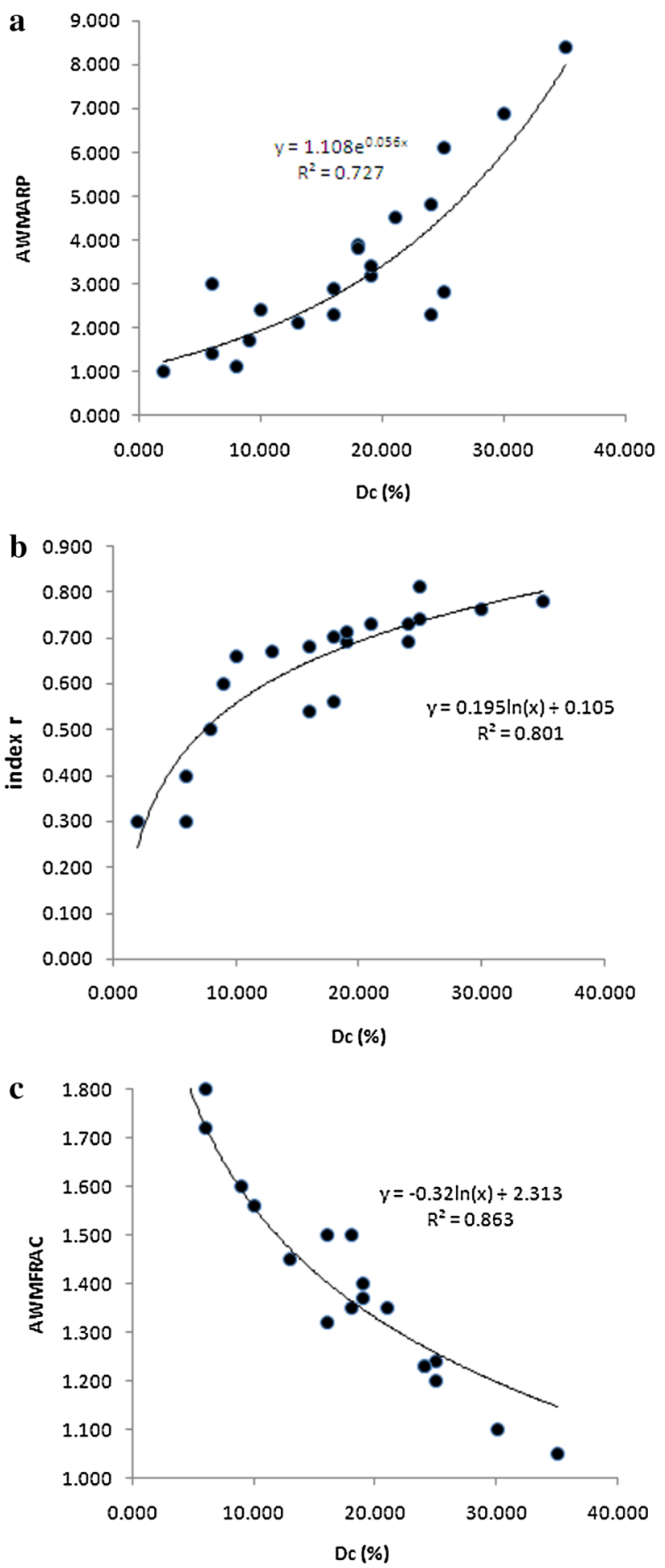

Fig. 4 Regression model for the soil cracks morphology

degree of complexity of the soil cracks also gradually decreases. Xiong et al. (2009) indicates that AWMARP growth rapidly during this process where, the narrower a given soil crack, the greater its complexity, and the wider a given soil crack, the less its complexity of soil cracks. 
Table 2 Regression equations for crack morphological indicators

\begin{tabular}{llll}
\hline Morphological indicator & Regression equation & $R^{2}$ & $P$ \\
\hline Index r & $\mathrm{Y}=0.195 \ln (\mathrm{x})+0.105$ & 0.801 & $<0.0001$ \\
AWMFRAC & $\mathrm{Y}=0.32 \ln (\mathrm{x})+2.313$ & 0.863 & $<0.0001$ \\
AWMARP & $\mathrm{Y}=1.108 \mathrm{e}^{0.056 \mathrm{x}}+2.313$ & 0.727 & $<0.0001$ \\
\hline$R^{2}$ correlation coefficient & & &
\end{tabular}

$R^{2}$ correlation coefficient

\begin{tabular}{lccllcr}
\hline & Length $(\mathrm{mm})$ & Width $(\mathrm{mm})$ & $\mathrm{D}_{\mathrm{c}}$ & AWMARP & AWMFRAC & Index r \\
\hline Mean & 127.0 & 3.690 & 17.2 & 3.4 & 1.436 & 0.627 \\
S.D. & 62.162 & 2.150 & 8.654 & 1.946 & 0.243 & 0.150 \\
Min & 3.0 & 0.300 & 2 & 1 & 1.05 & 0.3 \\
Max & 8.1 & 0.810 & 35 & 8.4 & 1.9 & 0.81 \\
CV $(\%)$ & 48.947 & 58.262 & 50.318 & 57.246 & 16.947 & 23.94 \\
Skewness & -1.179 & 0.421 & 0.115 & 1.163 & 0.454 & -1.170 \\
Kurtosis & -12.136 & -0.984 & -0.466 & 1.122 & -0.569 & 0.501 \\
\hline
\end{tabular}

However, quantification and characterization of desiccation crack network is an important aspect in the study of soil properties, and is helpful for evaluating the geotechnical properties of soil-water system. Perrier et al. (1995) reported that if the real structure features of crack networks can be determined, the soil's response to wetting and drying can be predicted. Structural cracks are of much interest for investigation of soil mechanics. In addition, the geometrical characteristics of crack network are related to the soil natural properties and environment conditions (Tang et al. 2008, 2010). Therefore, these results help to understand the soil properties and soil water conservation. The crack characteristics extracted by image processing techniques can well quantify the desiccation cracking process and distinguish the surface appearances of cracked soils with different geometric properties.

\section{Conclusions}

A computer aided image analysis program was used to determine geometric features of cracks, such as width, length, and surface area values, connectively and complexity from scanned photographs of the desiccation process. These parameters are important, because they influence both the soil hydraulics and mechanics. However, the development of cracks varies from soil to soil, even under the similar climatic condition. A decreasing trend was observed on connectivity throughout the cracking process, estimated by cracks intensity $\left(D_{c}\right)$, area-weighted mean ratio of soil-crack area to perimeter (AWMARP) and the area weighted mean of crack fractal dimension (AWMFRAC) values, it may be due to the number of trim cracks is abridged by the progression of crack development. On the other hand, $\mathrm{r}$ index which expresses connectivity of soil crack is also steadily expanded in the study site. In depth study is required to explore the connection between soil fracture mechanics and shrinkage characteristics over a range of water contents.

\section{References}

Adrian A, Karin A, Nadia A, Bernd D, Nick J, Christophe M, Peter N, Caroline W (2000) Comparison of the performance of pesticideleaching models on a cracking clay soil: results using the brimstone farm dataset. Agric Water Manag 44:85-104

Bandyopadhyay KK, Mohanty M, Painuli D, Misra AK, Hati KM, Mandal KG, Ghosh PK, Chaudhary RS, Acharya CL (2003) Influence of tillage practices and nutrient management on crack parameters in a vertisol of Central India. Soil Tillage Res 71:133-142

Bauer T, Strauss P (2014) A rule-based image analysis approach for calculating residuesand vegetation cover under field conditions. Catena 113:363-369

Bruand A, Cochrane H, Fisher P, Gilkes RJ (2001) Increase in the bulk density of a grey clay subsoil by infilling of cracks by topsoil. Eur J Soil Sci 52:37-47

Chen Yu, Ling C (1998) Fractal Geometry. Earthquake Press, Beijing, 3-25 (Ch)

Chenwuing L, Shihwei C, Wensheng Y et al (2003) Water infiltration rate in cracked paddy soil. Geoderma 117:169-181

Chertkov VY (2000) Using surface cracks spacing to predict crack network geometry in swelling soils. Soil Sci Soc Am J 64:1918-1921

Dasog GS, Shashidhara GB (1993) Dimension and volume of cracks in a Vertisol under different crop covers. Soil Sci 156(6): $424-428$

Gore A (2006) An inconvenient truth: the planetary emergency of global warming and what we can do about it. Rodale Press Inc., Pennsylvania

Jianhua R, Xiaojie L, Kai Z (2015) Quantitative analysis of relationships between crack characteristics and properties of 
soda-saline soils in Songnen plain, China. Chin Geogr Sci 25(5):591-601

Lakshmikantha MR, Prat PC, Ledesma A (2009) Image analysis for the quantification of a developing crack network on a drying soil. Geotech Test J 32(6):505-515

Lee BY, Kim YY, Yi ST, Kim JK (2013) Automated image processing technique for detecting and analysing concrete surface cracks. Struct Infrastruct Eng 9(6):567-577

Liu C, Shi B, Tang CS (2011) Quantification and characterization of microporosity by image processing, geometric measurement and statistical methods: application on SEM images of clay materials. Appl Clay Sci 54(1):97-106

Liu C, Tang CH, Shi B, Suo WB (2013) Automatic quantification of crack patterns by image processings. Comput Geosci 57:77-80

Novak V (1999) Soil-crack characteristics-estimation methods applied to heavy soils in the Nopex area. Agric For Meteorol 98:501-507

Perrier E, Mullon C, Rieu M (1995) Computer construction of fractal soil structures: simulation of their hydraulic and shrinkage properties. Water Resour Res 31(12):2927-2943

Roberto G (2002) Preferential flow in macroporous swelling soil with internal catchments: model development and applications. J Hydrol 269:150-168

Shit PK, Bhunia G, Maiti R (2014) Morphology and development of selected Badlands in South Bengal (India). Indian J Geogr Environ 13:161-171

Shit PK, Paira R, Bhunia GS, Maiti R (2015) Modeling of potential gully erosion hazard using geo-spatial technology at Garbheta block, West Bengal in India. Model Earth Syst Environ 1:2. doi:10.1007/s40808-015-0001-x
Tang C, Shi B, Liu C, Zhao L, Wang B (2008) Influencing factors of geometrical structure of surface shrinkage cracks in clayey soils. Eng Geol 101:204-217

Tang CS, Cui YJ, Tang AM, Shi B (2010) Experiment evidence on the temperature dependence of desiccation cracking behavior of clayey soils. Eng Geol 114:261-266

Tang CS, Shi B, Liu C, Suo WB, Gao L (2011) Experimental characterization of shrinkage and desiccation cracking in thin clay layer. Appl Clay Sci 52:69-77

Uday KV, Singh DN (2013) Investigation on cracking characteristics of fine-grained soils under varied environmental conditions. Dry Technol 31:1255-1266

Velde B (1999) Structure of surface cracks in soil and mud. Geoderma 93:101-124

Vogel HJ, Hoffmann H, Roth K (2005) Studies of crack dynamics in clay soil experimental methods, results, and morphological quantification. Geoderma 125:203-211

Xiong D, Lu X, Xian J, Zhou H, Yang Z (2008) Selection of judging indicators for surface morphology of soil crack under different development degrees in Yuanmou Arid-Hot Valley Region. J Nat Sci 13(3):363-368

Xiong D, Long Y, Yan D, Lu X, Ji Z, Fang H (2009) Surface morphology of soil cracks in Yuanmou Dry-hot Valley region, Southwest China. J Mt Sci 6:373-379

$\mathrm{Xu} \mathrm{J} \mathrm{(2002)} \mathrm{Mathematic} \mathrm{methods} \mathrm{in} \mathrm{contemporary} \mathrm{geography.} \mathrm{High}$ Education Press, Beijing, 251-304 (Ch)

Yoshida S, Adachi K (2004) Numerical analysis of crack generation in saturated deformable soil under row-planted vegetation. Geoderma 120:63-74 